\title{
Multivessel Disease Patients' Outcome and Second Generation Stent: Is Syntax Still a Valid Score? A Real-World Study from a Tertiary Center
}

\author{
Cristina Giglioli, Niccolò Marchionni, Alessio Mattesini, Chiara Zocchi, Manuel Biagioli, Marco Chiostri, \\ Salvatore Mario Romano, Emanuele Cecchi \\ Department of Cardiovascular and Thoracic Medicine, Azienda Ospedaliero-Universitaria Careggi, Florence, Italy \\ Correspondence: emanuelececchi@virgilio.it; Tel.: + 3955794 9577; Fax.: + 39557947617
}

Received: 1 September 2019; Accepted: 16 November 2020

\begin{abstract}
Objective. The SYNTAX trial was designed to evaluate whether multivessel disease patients could benefit from percutaneous or surgical revascularization using a paclitaxel eluting stents, but after the introduction of second generation stents, this score needs to be reevaluated. The aim of our study was to analyze the association between SYNTAX score and the prognosis of multivessel patients submitted to percutaneous coronary intervention (PCI) and second generation everolimus eluting stents (EES) implantation. Materials and Methods. Data on 289 patients with multivessel coronary artery disease submitted to PCI with EES were stored in a dedicated database and retrospectively analyzed. During a mean follow-up period of $14.4 \pm 6.4$ months, major adverse cardiac and cerebrovascular events (MACCE) including death from any cause, myocardial infarction, target lesion revascularization (TLR) and stroke, were systematically assessed. Results. The incidence of MACCE at follow-up was $13.1 \%$; death from any cause occurred in 19 patients (6.6\%) and myocardial infarction in 9 patients (3.1\%). TLR was detected in $2.7 \%$ of patients and stroke was observed in 2 patients. The SYNTAX score did not prove to be an independent predictor of overall death at multivariable analysis. Conclusion. At mid-term follow-up, the incidence of MACCE in multivessel disease patients submitted to PCI and EES implantation was low; no significant association was found between SYNTAX score severity and MACCE at follow-up, suggesting that it should be modified after the introduction of EES.
\end{abstract}

Key Words: Multivessel Disease • Percutaneous Coronary Intervention • SYNTAX Trial • Dual Antiplatelet Therapy • Outcome.

\section{Introduction}

Revascularization treatments for patients with complex coronary lesions are continuously evolving and new scores to choose the best approach for revascularization have been investigated. Despite this, the indications for coronary revascularization continue to be debated between interventional cardiologists and surgeons, who have experience with new drugeluting stents (DES) and percutaneous coronary intervention (PCI) techniques, as well as new coronary artery bypass graft (CABG) strategies, in their daily practice. In the Synergy between PCI with Taxus and Cardiac Surgery (SYNTAX) trial (1) PCI with paclitaxel eluting stents (PES) was compared to $\mathrm{CABG}$ as the primary treatment option for patients with de novo coronary three-vessel disease, and/or left main (LM) disease. CABG resulted in significantly more favourable outcomes for the incidence of target lesion revascularization (TLR), and major adverse cardiac and cerebrovascular events (MACCE), after twelve months in patients with a SYNTAX score $\geq 33$ (2). The SYNTAX score is a tool to characterize coronary anatomy on the basis of nine anatomical criteria, including the number, the site and the complexity of coronary lesions, obtaining a score for each lesion and an overall score for each patient. The score obtained is divided into three classes [low ( $\leq 22)$, intermediate (23-32) and high $(\geq 33)$ ]. Apart from patients with low SYNTAX score $(\leq 22)$ for whom PCI is preferred over CABG, for patients with a SYNTAX score of 23-32, the SYNTAX trial does not furnish strict recom- 
mendations, reporting only a higher, though not significantly, incidence of MACCE in PCI patients (16.7\% versus $12.4 \%$ in CABG patients) (1). Recent data reporting the 5 year follow-up of this trial have shown that in patients with a SYNTAX score higher than 22, CABG with respect to PCI demonstrated clear superiority in terms of MACCE, death, MI, and repeat revascularization (3). Nevertheless, previous studies demonstrated that the introduction of everolimus eluting stents (EES) has been associated with a reduction in events with respect to PES (4-6), suggesting that the use of the anatomical SYNTAX score needs to be reevaluated. Moreover, in a wide open-label randomized trial, PCI with EES in patients with multivessel coronary artery disease was not inferior in respect to $\mathrm{CABG}$, despite a similar anatomical SYNTAX score (7).

In addition to this, other SYNTAX derived scores have been developed in the last few years to better guide decision-making between CABG and PCI, that combine the anatomical SYNTAX score with other clinical variables $(8,9)$ and have been demonstrated superior to the purely angiographic score $(10,11)$.

The aim of our study was to evaluate the association between the SYNTAX score and the outcome of 289 unselected multivessel patients, consecutively submitted to PCI and EES implantation in the General Cardiology Unit of the Department of Cardiovascular and Thoracic Medicine of the Azienda Ospedaliero-Universitaria Careggi in Florence (Italy).

\section{Material and Methods}

\section{Patient Population and Study Design}

In our study we analyzed the data of 349 patients with multivessel coronary artery disease who were admitted to the General Cardiology Unit of the Department of Cardiovascular and Thoracic Medicine of the Azienda Ospedaliero-Universitaria Careggi in Florence (Italy) from January 2010 to December 2010 for stable angina (SA) $(\mathrm{N}=88)$, non-ST acute coronary syndrome (NSTACS $)(\mathrm{N}=182)$ or ST elevation myocardial infarction (STEMI) ( $\mathrm{N}=79)$. Among these, 289 patients (83\%) underwent PCI and 60 (17\%) CABG, and the latter were excluded from the analysis, which was based on PCI patients alone. The selection of patients for CABG was based not only on the SYNTAX score (mean $43.8 \pm 10.3$ ) but also on clinical and instrumental assessment, taking into consideration the presence of a concomitant valvulopathy, the possible contraindications to dual antiplatelet therapy (DAPT), or the presence of comorbidities. The clinical, biohumoral and angiographic data of multivessel patients submitted to PCI were collected and stored in a dedicated database and analyzed retrospectively. In particular, data on gender, age, arterial hypertension, obesity (defined as a body mass index $>30 \mathrm{Kg} / \mathrm{m}^{2}$ ), diabetes mellitus, dyslipidemia, smoking habit, chronic obstructive pulmonary disease, and a family history of cardiovascular disease were collected. The presence of peripheral arteriopathy was diagnosed by means of Doppler ultrasound. Renal failure was defined as an estimated glomerular filtration rate (eGFR) $<30 \mathrm{ml} / \mathrm{min}$ measured using Cockroft-Gault equation. The EuroSCORE I was calculated as previously reported (12). Doppler echocardiography was performed in all patients to exclude the presence of severe valvulopathy, as well as to evaluate left ventricular ejection fraction. Blood chemistry included the measurement of troponin I, CK-MB, creatine phosphokinase and creatinine values.

Coronary angiography and PCI were performed as previously described according to the International Guidelines (13); in the majority of patients (92.3\%) radial access was employed. In 104 patients (35.9\%), PCI was staged in several sessions depending on lesion complexity, hemodynamic status or associated renal failure; exclusively Xience V everolimus stents were implanted in all patients. This kind of stents was the only second generation stent available in our hospital during the study period.

Chronic total occlusion (CTO) was defined as the complete occlusion of the vessel by heavy atherosclerotic plaque that had been present for at least 3 months. Vessels with CTO were treated with PCI only after demonstration of ischemia viability in the segment of the myocardium supplied by the index vessel, and in the presence of favourable anatomical characteristics. A revascularization was defined "complete" if all stenotic vessels $\geq 2.5 \mathrm{~mm}$ were revascularized (anatomic revascularization) (14). 


\section{SYNTAX Score Calculation}

The SYNTAX score is a tool to characterize coronary anatomy on the basis of nine anatomical criteria, including the number, the site and the complexity of coronary lesions, obtaining a score for each lesion and an overall score for each patient (1). The score is given by the sum of the scores of each individual lesion $>50 \%$ in vessels with a diameter $>1.5 \mathrm{~mm}$. The coronary tree is divided into 16 segments based on the AHA classification. Each segment is assigned a score of 1 or 2 which is based on the presence or absence of atherosclerotic disease, and this score is weighed on the location of the disease in the different coronary segments (from 3.5 for the proximal left anterior descending to 5.0 for the left main). Vessels less than $1.5 \mathrm{~mm}$ in diameter are not included in the score calculation. A multiplication factor of $\mathrm{x} 2$ is used for nonocclusive and x 5 for total occlusions, reflecting the difficulty of the angioplasty revascularization procedure. The computerized algorithm calculates the total score based on 12 main questions that can be divided into two groups. The first three questions determine the coronary dominance, the total number of lesions and the coronary segments involved. The other nine questions refer to the morphological characteristics of the lesions and are repeated for each lesion. For example, one point is given for bifurcations of type A, B or C, 2 points for $\mathrm{D}, \mathrm{E}, \mathrm{F}$, or $\mathrm{G}$, and one point is given for bifurcation angles greater than $70^{\circ}$. The scores obtained with the SYNTAX score can be divided into 3 classes, [low ( $\leq 22)$, intermediate (23-32) and high $(\geq 33)$ ]. A high SYNTAX score, indicating a more complex coronary picture, suggests the high risk of submitting the patient to a mechanical revascularization strategy, and is related to a poor prognosis (therefore CABG is better), while a low score favours PCI. An important feature of the score is that it is weighed exclusively on anatomical lesion criteria, and a separate score is calculated for each lesion. The total score is then calculated from the sum of the individual scores.

\section{Antiplatelet Therapy and Other Therapeutic Measures}

All patients received a loading dose of acetilsalycilic acid (ASA) $325 \mathrm{mg}$ and clopidogrel $300 \mathrm{mg}$ the day before the PCI in the elective procedures, and a loading dose of ASA $325 \mathrm{mg}$ and clopidogrel $600 \mathrm{mg}$ in the catheterization laboratory for urgent PCI. After the procedure, all patients were treated with ASA $100 \mathrm{mg}$ /day and clopidogrel $75 \mathrm{mg} /$ day. Moreover, in these patients platelet aggregation was evaluated with Light Transmittance Aggregometry (LTA) induced by ADP (10 micromol/L) and arachidonic acid $(2 \mathrm{mmol} / \mathrm{L})$ in platelet rich plasma, in order to estimate the Residual Platelet Activity (RPA) on antiplatelet therapy (15). Responders were identified by a RPA $<70 \%$ for ADP and $<20 \%$ for arachidonic acid (15). Non-responder patients were switched from clopidogrel to prasugrel (that was the only alternative P2Y12 receptor inhibitor available at the time of the study), and from ASA $100 \mathrm{mg}$ to a higher dose (160-325 mg), as previously reported (16).

To prevent contrast induced nephropathy (CIN), elective patients underwent hyper-hydration with saline solution and intravenous administration of N-Acetyl Cisteyn $600 \mathrm{mg}$ twice/day. Patients affected by Chronic Renal Failure with eGFR $<30 \mathrm{ml} / \mathrm{min}$ were submitted to continuous renal replacement therapy (CRRT) before and after contrast medium administration (13).

All patients gave their informed consent for participation in the study, and all the procedures followed were in accordance with the ethical standards of the responsible committee on human experimentation, and with the Helsinki Declaration of 1975, as revised in 1983 .

\section{Follow-Up}

Clinical follow-up was scheduled at 1, 6 and 12 months, and performed in all 289 patients (100\%) by independent research personnel who were unaware of the study objectives. During the scheduled visit electrocardiography and Doppler echocardiography were performed. A stress test was scheduled in all patients in the following 6-12 months, 
and coronary angiography was only performed in patients with documented ischemia or those who had undergone very complex procedures, or who had unequivocal clinical symptoms of angina. In case of hospitalization, data were obtained by a systematic review of the hospital records.

The primary end-point of the study included MACCE, consisting in death from any cause, myocardial infarction, TLR and stroke as in the SYNTAX trial, and the secondary end-point included cardiovascular death, stable angina, CIN and bleedings, and their correlation with SYNTAX score.

Data regarding the primary and secondary end-points were systematically assessed during a mean follow-up period of $14.4 \pm 6.4$ months.

Myocardial infarction was defined after the detection of a rise and/or fall in cardiac biomarker values [preferably cardiac troponin I (TnI)] with at least one value above the $99^{\text {th }}$ percentile upper reference limit and with at least one of the following: 1) symptoms of ischemia; 2) new or presumed new significant ST-segment - T wave changes or new left bundle branch block; 3) development of pathological Q waves in the ECG; 4) imaging evidence of new loss of viable myocardium or new regional wall motion abnormality; 5) identification of an intracoronary thrombus by angiography or autopsy (17).

TLR was defined as a PCI of the target lesion due to restenosis or re-occlusion within the stent or in an adjacent segment of $5 \mathrm{~mm}$ distally or proximally to the edges of the stent (18). Stroke was defined as rapidly developing clinical signs of focal (or global) disturbance of cerebral function, lasting more than 24 hours or leading to death, with no apparent cause other than that of vascular origin. Cardiovascular death was defined as death resulting from an acute myocardial infarction, sudden cardiac death or death due to heart failure, stroke, cardiovascular procedures, cardiovascular haemorrhage, and to other cardiovascular causes. Stable angina was defined as chest pain or discomfort occurring most often with activity or emotional stress.

CIN was defined as a $25 \%$ increase in creatinine compared to its baseline value after PCI. Major bleedings were classified according to TIMI criteria as a decrease in haemoglobin $>5 \mathrm{~g} / \mathrm{dl}$ or at least $15 \%$ in haematocrits; minor bleedings were classified according to TIMI criteria as a decrease in haemoglobin $>3 \mathrm{~g} / \mathrm{dl}$ or at least $10 \%$ in hematocrits (19). Follow-up data were obtained either by hospital records or by phone by two physicians unaware of the patients' in-hospital course, and were verified by the Registry Office of the Florence Health Authority.

\section{Statistical Analysis}

Data were stored in a dedicated database and analyzed with the IBM-SPSS 20.0 statistical package (SPSS Inc. Chicago, IL, USA). Continuous variables were tested for normality with the KolmogorovSmirnov one sample test, and reported as mean \pm SD or median and interquartile range when appropriate. Categorical variables were expressed as frequency and/or percentage. Between-group comparisons were performed with Student's $t$ and chisquare (or Fisher's when needed) tests, respectively. A two-tailed p-value less than 5\% was considered significant. Unadjusted OR and their relative 95\% confidence intervals for the occurrence of MAC$\mathrm{CE}$ were calculated either considering a one unit step increase in the SYNTAX score and different classes of SYNTAX score [class $2(23-32)$ vs. class $1(\leq 22)$, class $3(\geq 33)$ vs. class $1(\leq 22)$ and class 3 ( $\geq 33$ ) vs. class 2 (23-32)] for each cardiovascular event. Outcomes which were significantly associated with SYNTAX score (one unit step increase) at univariate analysis were further adjusted at multivariable analysis for clinical, angiographic and laboratory data related to the antiplatelet response significantly associated with the outcome examined at univariate analysis. Multivariable analysis was performed to evaluate the independent association between adverse events significanly associated with the SYNTAX score at univariate analysis, and other clinical, angiographic and laboratory data significantly associated with the outcome analyzed at univariate analysis. Considering overall death as an independent variable, we adjusted the analysis for renal dysfunction, EuroSCORE I and response to ADP. Taking into account the number of events (19 overall deaths occurred at follow-up) only two predictors were added simultaneously to the 
model of multivariable analysis. A ROC curve was built to evaluate the value of SYNTAX score with a higher specificity/sensitivity ratio in predicting cardiovascular events.

\section{Results}

The baseline clinical characteristics of patients submitted to PCI and analyzed in the study are reported in Table 1.

Table 1. Baseline Clinical and Laboratory Characteristics with Data Related to Response to Standard Antiplatelet Therapy of Multivessel Patients Submitted to PC

\begin{tabular}{|c|c|}
\hline Characteristics & $\mathrm{PCl}$ patients $(\mathrm{N}=289)$ \\
\hline Age (years), mean $\pm S D$ & $69 \pm 11$ \\
\hline Male gender, N (\%) & $219(75.8)$ \\
\hline \multicolumn{2}{|l|}{ Admission diagnosis, $\mathrm{N}(\%)$} \\
\hline STEMI & $73(25.3)$ \\
\hline ACS & $142(49.1)$ \\
\hline Stable angina & $74(25.6)$ \\
\hline \multicolumn{2}{|l|}{ Cardiovascular risk factors, $\mathrm{N}(\%)$} \\
\hline Arterial hypertension & $215(74.4)$ \\
\hline Obesity (BMI >30 kg/m²) & $37(12.8)$ \\
\hline Diabetes mellitus & $93(32.2)$ \\
\hline Dyslipidemia & $149(51.6)$ \\
\hline Smoking habit & $152(52.6)$ \\
\hline Family history of cardiovascular disease & $101(34.9)$ \\
\hline \multicolumn{2}{|l|}{ Comorbidities } \\
\hline Peripheral arteriopathy, $\mathrm{N}(\%)$ & $118(40.8)$ \\
\hline Renal failure (eGFR <30 ml/min), N (\%) & $23(8.0)$ \\
\hline COPD, N (\%) & $33(11.4)$ \\
\hline EuroSCORE I, median ( $25^{\text {th }}-75^{\text {th }}$ percentile) & $9.61(0.88 ; 59.33)$ \\
\hline \multicolumn{2}{|l|}{ Clinical history, N (\%) } \\
\hline Heart failure & $32(11.1)$ \\
\hline Associated valvulopathy & $4(1.3)$ \\
\hline Previous MI & $57(19.7)$ \\
\hline Previous $\mathrm{PCl}$ & $89(30.8)$ \\
\hline \multicolumn{2}{|l|}{ Blood chemistry } \\
\hline Tnl peak (mcg/L), median $\left(25^{\text {th }}-75^{\text {th }}\right.$ percentile) & $5.29(0.67-43.76)$ \\
\hline CK-MB peak ( $\mathrm{ng} / \mathrm{mL})$, median $\left(25^{\text {th }}-75^{\text {th }}\right.$ percentile) & $16.6(4.25-76.65)$ \\
\hline CPK peak (U/L), median ( $25^{\text {th }}-75^{\text {th }}$ percentile) & $346.0(120.5-1109.0)$ \\
\hline Creatinine $(\mathrm{mg} / \mathrm{dL})$, mean $\pm \mathrm{SD}$ & $1.4 \pm 0.6$ \\
\hline \multicolumn{2}{|l|}{ Response to antiplatelet therapy } \\
\hline \multicolumn{2}{|l|}{ Response to ADP, N (\%) } \\
\hline RPA $>70 \%$ (responder to clopidogrel) & $234(80.9)$ \\
\hline RPA $<70 \%$ (not responder to clopidogrel) & $55(19.0)$ \\
\hline Shift to Prasugrel, N (\%) & $53(18.3)$ \\
\hline \multicolumn{2}{|l|}{ Response to Arachidonic Acid, N (\%) } \\
\hline RPA $<20 \%$ (responder to ASA) & $210(72.6)$ \\
\hline RPA $>20 \%$ (not responder to ASA) & $79(27.3)$ \\
\hline Shift to higher-dose aspirin, N (\%) & $27(9.3)$ \\
\hline
\end{tabular}

Continuous variables are presented as mean \pm 1 SD or median $\left(25^{\text {th }}-75^{\text {th }}\right.$ percentile); discrete variables are presented as $\mathrm{N}$ (percentage). $\mathrm{PCl}=\mathrm{Percutaneous}$ coronary intervention; STEMI=ST elevation myocardial infarction; $\mathrm{ACS}=\mathrm{Acute}$ coronary syndrome; $\mathrm{BMI}=\mathrm{Body}$ mass index; $\mathrm{COPD=Chronic}$ obstructive pulmonary disease; $\mathrm{eGFR}=$ estimated Glomerular filtration rate; $\mathrm{Ml}=$ Myocardial infarction; $\mathrm{TnI}=$ Troponin I; $\mathrm{CK}-\mathrm{MB}=\mathrm{Creatine}$ phosphokinase-MB; $\mathrm{CPK}=\mathrm{Creatine}$ phosphokinase; $A D P=$ Adenosine diphosphate; RPA= Residual platelet activity; ASA=Acetylsalicylic acid. 
Table 2. Angiographic Data and Adverse Events at FollowUp of Multivessel Patients Submitted to PCI

\begin{tabular}{|c|c|}
\hline Variables & $\mathrm{PCl}$ patients $\mathrm{N}=289$ \\
\hline SYNTAX score, mean \pm SD & $24.52 \pm 7.18$ \\
\hline \multicolumn{2}{|l|}{ SYNTAX score classes, N (\%) } \\
\hline$\leq 22$ & $84(29.0)$ \\
\hline $23-32$ & $145(50.1)$ \\
\hline$>33$ & $60(20.7)$ \\
\hline 3-vessel disease, N (\%) & $178(61.6)$ \\
\hline 2-vessel disease, N (\%) & $111(38.4)$ \\
\hline \multicolumn{2}{|l|}{ Critical stenoses, N (\%) } \\
\hline Total & $525(100)$ \\
\hline LM & $23(7.9)$ \\
\hline LAD & $193(66.7)$ \\
\hline $\mathrm{CX}$ & $162(56.0)$ \\
\hline RCA & $147(50.8)$ \\
\hline \multicolumn{2}{|l|}{ Chronically occluded vessels, N (\%) } \\
\hline Total & $49(16.9)$ \\
\hline LM & 0 \\
\hline LAD & $11(3.8)$ \\
\hline $\mathrm{CX}$ & $14(4.8)$ \\
\hline RCA & $24(8.3)$ \\
\hline Total stents implanted $(\mathrm{N})$ & 708 \\
\hline Complete revascularization, $\mathrm{N}(\%)$ & $250(86.5)$ \\
\hline Stents length $(\mathrm{mm})$, mean $\pm \mathrm{SD}$ & $51.32 \pm 31.23$ \\
\hline Post procedural TIMI flow grade III, N (\%) & $547(99.8)$ \\
\hline \multicolumn{2}{|l|}{ Primary Outcomes, N (\%) } \\
\hline MACCE & $38(13.1)$ \\
\hline Death from any cause & $19(6.6)$ \\
\hline Target lesion revascularization & $8(2.7)$ \\
\hline Myocardial infarction & $9(3.1)$ \\
\hline Stroke & $2(0.7)$ \\
\hline \multicolumn{2}{|l|}{ Secondary Outcomes, N (\%) } \\
\hline Cardiovascular death & $13(4.5)$ \\
\hline Stable angina & $19(6.6)$ \\
\hline Contrast induced nephropathy & $21(7.3)$ \\
\hline Bleedings & $4(1.4)$ \\
\hline \multicolumn{2}{|l|}{ Others } \\
\hline $\begin{array}{l}\text { Left ventricular ejection fraction (\%), } \\
\text { mean } \pm \text { SD }\end{array}$ & $48 \pm 14$ \\
\hline $\begin{array}{l}\text { Length of hospital stay (days), mean } \\
\pm S D\end{array}$ & $9.0 \pm 2.3$ \\
\hline
\end{tabular}

Continuous variables are presented as mean $( \pm S \mathrm{~S})$; Categorical variables are presented as $\mathrm{N}$ (percentage). $\mathrm{PCl}=$ Percutaneous coronary intervention; $\mathrm{LM}=$ Left main; $\mathrm{LAD}=\mathrm{Left}$ anterior descending artery; $C X=$ Circumflex artery; $\mathrm{RCA}=$ Right coronary artery; $\mathrm{TIMI}=$ Thrombolysis in myocardial infarction; MACCE=Major adverse cardiac and cerebrovascular events.
Table 2 shows the angiographic characteristics of patients who underwent PCI. About $70 \%$ of patients had a SYNTAX score higher than $22 ; 62 \%$ of patients had three vessel disease and left main was involved in $7.9 \%$ of patients. Complete revascularization was obtained in a high percentage of patients (86.5\%). In 21 out of 49 patients with CTO (42.8\%), the CTO was not treated with PCI because of the lack of demonstration of ischemia/viability in the corresponding myocardial segment. In the remaining 28 patients, ischemia/viability was demonstrated and 17 of them $(60.8 \%)$ were successfully treated with PCI. Nineteen percent of patients showed a high RPA by ADP, and 27.3\% by arachidonic acid: most of them were shifted to prasugrel and/or to a higher dose of ASA to obtain a RPA $<70 \%$ for ADP and $<20 \%$ for arachidonic acid, when not contraindicated. None of the patients in whom CIN occurred underwent chronic hemodialysis.

During a mean follow-up of $14.4 \pm 6.4$ months, the incidence of MACCE (death from any cause, myocardial infarction, TLR and stroke) was $13.1 \%$ and TLR was detected in $2.7 \%$ of patients (Table $1)$. No patient developed any definite stent thrombosis, only one patient $(0.3 \%)$ presented a possible stent thrombosis. Moreover, the incidence of bleedings was $1.4 \%$, occurring in 4 patients: 2 patients developed major bleeding and other 2 patients developed minor bleeding.

No significant differences were observed in the clinical, angiographic and laboratory data between patients experiencing MACCE and those who did not, except for a higher prevalence of severe renal dysfunction $(\mathrm{P}<0.001)$, higher mean values of the EuroSCORE I $(\mathrm{P}<0.001)$ and higher values of residual platelet reactivity by $\mathrm{ADP}(\mathrm{P}=0.011)$, as an index of poor response to clopidogrel, in patients in whom MACCE occurred (Table 3).

Moreover, we evaluated the SYNTAX score as a predictor of adverse events at univariate analysis (Table 4 Panel A). Considering MACCE as a composite end-point we did not observe any relationship with the different classes of the SYNTAX score. Accordingly, when we considered the single adverse events that composed the pri- 
Table 3. Clinical Data, Angiographic Variables and Antiplatelet Response Values in Relation to Major Cardiac and Cardiovascular Events

\begin{tabular}{|c|c|c|c|}
\hline Variables & $\begin{array}{l}\text { No MACCE } \\
\mathrm{N}=251(86.9 \%)\end{array}$ & $\begin{array}{l}\text { MACCE } \\
\mathrm{N}=38(13.1 \%)\end{array}$ & $P$ value \\
\hline \multicolumn{4}{|l|}{ Cardiovascular risk factors, $\mathrm{N}(\%)$} \\
\hline Arterial hypertension & $186(74.1)$ & $29(76.3)$ & 0.771 \\
\hline Diabetes mellitus & $76(30.3)$ & $17(44.7)$ & 0.075 \\
\hline Dyslipidemia & $130(51.8)$ & $19(50.0)$ & 0.837 \\
\hline Smoking habit & $134(53.4)$ & $18(47.4)$ & 0.489 \\
\hline Family history of cardiovascular disease & 89 (35.5) & $12(31.6)$ & 0.640 \\
\hline \multicolumn{4}{|l|}{ Comorbidities } \\
\hline Peripheral arteriopathy, $\mathrm{N}(\%)$ & $36(14.3)$ & $8(21.1)$ & 0.283 \\
\hline Renal failure (eGFR <30 ml/min), $\mathrm{N}(\%)$ & $15(6.0)$ & $8(21.1)$ & $<0.001$ \\
\hline Chronic obstructive pulmonary disease, $\mathrm{N}(\%)$ & $26(10.4)$ & $7(18.4)$ & 0.145 \\
\hline EuroSCORE I (units), mean \pm SD & $8.29 \pm 9.02$ & $18.14 \pm 16.00$ & $<0.001$ \\
\hline \multicolumn{4}{|l|}{ Angiographic data } \\
\hline SYNTAX score (units), mean \pm SD & $24.6 \pm 7.1$ & $26.7 \pm 8.4$ & 0.169 \\
\hline Left main involvement, $\mathrm{N}(\%)$ & $20(8.0)$ & $3(7.9)$ & 0.988 \\
\hline 2-vessel disease, $\mathrm{N}(\%)$ & $99(39.4)$ & $11(28.9)$ & \multirow{2}{*}{0.214} \\
\hline 3-vessel disease, $\mathrm{N}(\%)$ & $152(60.6)$ & $27(31.1)$ & \\
\hline Stents implanted (N), mean \pm SD & $1.86 \pm 0.95$ & $1.90 \pm 1.08$ & 0.865 \\
\hline \multicolumn{4}{|l|}{ Antiplatelet therapy, mean \pm SD } \\
\hline Response to ADP - RPA (\%) & $49.5 \pm 19.3$ & $58.2 \pm 17.9$ & 0.011 \\
\hline Response to Arachidonic acid - RPA (\%) & $20.3 \pm 15.0$ & $24.4 \pm 18.4$ & 0.142 \\
\hline
\end{tabular}

Continuous variables are presented as mean ( $\pm 1 \mathrm{SD}$ ); Discrete variables are presented as frequency (percentage). eGFR=estimated Glomerular filtration rate; $\mathrm{ADP}=$ Adenosine diphosphate; $\mathrm{RPA}=$ Residual platelet activity.

mary end-point MACCE (death from any cause, myocardial infarction, TLR and stroke) and the secondary end-point (stable angina, CIN, cardiovascular death and bleedings) comparing patients with low-SYNTAX score (0-22) and intermediate SYNTAX score (23-32), no significant difference in event rates between the two groups was observed. In contrast, when we compared patients with high SYNTAX score $(\geq 33)$ with patients with low SYNTAX score (0-22) we observed a significant difference between the two groups in relation to death from any cause and CIN that was higher in patients with SYNTAX score $\geq 33$. Considering instead SYNTAX score by unit step increase (Table 4 Panel B) we observed a significant increase in death from any cause and cardiovascular death.

However, at multivariable analysis, EuroSCORE I (1 unit step) was shown to be the only independent predictor of overall mortality after adjustment for renal failure, response to ADP (1\% step) and SYNTAX score (1 unit step) in a model in which variables were added separately $(\mathrm{P}<0.001$ in comparison with all the variables), while SYNTAX score was not shown to be independently associated with death from any cause after adjustment for EuroSCORE I (OR 1.05 95\%CI 0.98-1.13, $\mathrm{P}=0.179$ ).

Finally, it was possible to identify a cut-off value of SYNTAX score by ROC curve analysis, under which the risk of adverse events was lower. In fact, the best specificity and the best sensitivity of SYNTAX score to cardiovascular events was 29.75 (Figure 1). The ROC curve (outcome: MACCE) for SYNTAX score showed an AUC of $0.68(95 \%$ CI 0.53 to $0.83, \mathrm{P}=0.028)$ with a value of 29.75 as the best discriminant (sensitivity $54 \%$, specificity $79 \%)$. 
Acta Medica Academica 2020;49(3):265-277

Table 4. Association between Syntax Score, Either Considered by Classes ( $\leq 22,22-32$ and $\geq 33$ ) (Panel A) and by One Unit Step Increase (Panel B), and Adverse Events

Panel A

\begin{tabular}{|c|c|c|c|}
\hline Adverse Events in relation to Syntax Score Classes & Unadjusted OR & $95 \% \mathrm{Cl}$ & $P$ value \\
\hline \multicolumn{4}{|l|}{ MACCE $(\mathrm{N}=38)$} \\
\hline Class 2 (23-32) vs. Class 1 ( $\leq 22)$ & 1.01 & $0.42-2.40$ & 0.982 \\
\hline Class 3 ( $\geq 33$ ) vs. Class $1(\leq 22)$ & 2.15 & $0.84-5.52$ & 0.111 \\
\hline \multicolumn{4}{|l|}{ Death from any cause $(\mathrm{N}=19)$} \\
\hline Class 2 (23-32) vs. Class $1(\leq 22)$ & 2.66 & $0.56-12.62$ & 0.218 \\
\hline Class 3 ( $\geq 33$ ) vs. Class $1(\leq 22)$ & 6.50 & $1.33-31.90$ & 0.021 \\
\hline \multicolumn{4}{|l|}{$\operatorname{TLR}(\mathrm{N}=8)$} \\
\hline Class 2 (23-32) vs. Class $1(\leq 22)$ & 0.14 & $0.02-1.24$ & 0.076 \\
\hline Class 3 ( $\geq 33$ ) vs. Class $1(\leq 22)$ & 0.70 & $0.12-3.98$ & 0.691 \\
\hline \multicolumn{4}{|l|}{ Myocardial Infarction $(\mathrm{N}=9)$} \\
\hline Class $2(23-32)$ vs. Class $1(\leq 22)$ & 0.85 & $0.14-5.18$ & 0.858 \\
\hline Class 3 ( $\geq 33$ ) vs. Class $1(\leq 22)$ & 3.00 & $0.53-16.98$ & 0.214 \\
\hline Stroke $(\mathrm{N}=2)$ & \multicolumn{3}{|c|}{ NA (only 2 cases observed, all of them in Class 2) } \\
\hline \multicolumn{4}{|l|}{ Cardiovascular death $(\mathrm{N}=13)$} \\
\hline Class $2(23-32)$ vs. Class $1(\leq 22)$ & 4.13 & $0.50-34.16$ & 0.189 \\
\hline Class 3 ( $\geq 33$ ) vs. Class $1(\leq 22)$ & 7.75 & $0.88-68.22$ & 0.065 \\
\hline \multicolumn{4}{|l|}{ Stable Angina $(\mathrm{N}=19)$} \\
\hline Class $2(23-32)$ vs. Class $1(\leq 22)$ & 1.04 & $0.37-2.94$ & 0.936 \\
\hline Class 3 ( $\geq 33$ ) vs. Class $1(\leq 22)$ & 0.46 & $0.09-2.35$ & 0.349 \\
\hline \multicolumn{4}{|l|}{$\mathrm{CIN}(\mathrm{N}=8)$} \\
\hline Class $2(23-32)$ vs. Class $1(\leq 22)$ & 1.96 & $0.52-7.34$ & 0.318 \\
\hline Class 3 ( $\geq 33$ ) vs. Class $1(\leq 22)$ & 4.28 & $1.08-16.92$ & 0.038 \\
\hline \multicolumn{4}{|l|}{ Bleedings $(\mathrm{N}=4)$} \\
\hline Class $2(23-32)$ vs. Class $1(\leq 22)$ & 0.56 & $0.08-4.06$ & 0.567 \\
\hline Class 3 ( $\geq 33$ ) vs. Class $1(\leq 22)$ & No bleeding in Class 3 & & \\
\hline
\end{tabular}

\section{Panel B}

\begin{tabular}{|c|c|c|c|c|}
\hline \multirow{2}{*}{ Adverse Events } & PCl pts $\mathrm{N}=289$ & \multirow{2}{*}{ Unadjusted OR } & \multirow{2}{*}{$95 \% \mathrm{Cl}$} & \multirow{2}{*}{$P$ value } \\
\hline & $\mathrm{N}(\%)$ & & & \\
\hline MACCE & $38(13.1)$ & 1.04 & $0.99-1.09$ & 0.115 \\
\hline Death from any cause & $19(6.6)$ & 1.08 & $1.02-1.15$ & 0.012 \\
\hline TLR & $8(2.7)$ & 0.97 & $0.88-1.08$ & 0.629 \\
\hline Myocardial Infarction & $9(3.1)$ & 1.06 & $0.97-1.15$ & 0.206 \\
\hline Stroke & $2(0.7)$ & 1.03 & $0.86-1.24$ & 0.755 \\
\hline Cardiovascular death & $13(4.5)$ & 1.09 & $1.01-1.17$ & 0.022 \\
\hline Stable Angina & $19(6.6)$ & 0.99 & $0.93-1.06$ & 0.796 \\
\hline CIN & $21(7.3)$ & 1.06 & $0.99-1.12$ & 0.062 \\
\hline Bleedings & $4(1.4)$ & 0.87 & $0.74-1.03$ & 0.111 \\
\hline
\end{tabular}

$\mathrm{PCl}=$ Percutaneous coronary intervention; MACCE=Major adverse cardiac and cardiovascular events; TLR=Target lesion revascularization; NA=Not applicable; $\mathrm{CIN}=$ Contrast induced nephropathy. 


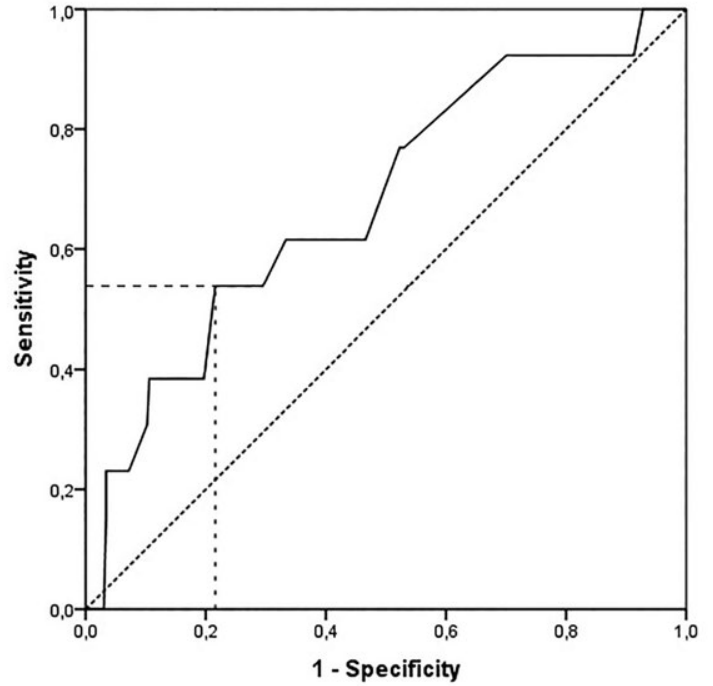

Figure 1. Analysis by ROC Curve of the Optimal Cut-Off Value of SYNTAX Score for the Occurrence of Major Cardiac and Cardiovascular Events.

\section{Discussion}

The main finding of the present study was that, in our study population, the different classes of SYNTAX score, as defined in the homonymous trial (1) did not result clearly related to the adverse events at mid-term follow-up. On univariate analysis, when we considered overall MACCE as a composite end-point, we did not observe any relationship with any class of the SYNTAX score. On the contrary, when we considered the single adverse events that composed MACCE (death from any cause, myocardial infarction, TLR and stroke), the patients in class 3 showed a higher incidence of deaths from any cause in comparison with the patients in classes 1 and 2. However, on multivariable analysis, the SYNTAX score did not prove to be an independent predictor of overall mortality at midterm follow-up after adjustment for other variables. It should also be noted that, in our case series, overall and cardiovascular mortality were higher than that in the SYNTAX trial, and this may have several explanations. First, in our study there was a higher percentage of acute coronary syndrome (ACS) patients than in the SYNTAX trial; about $75 \%$ of patients enrolled were ACS and a quarter of them were STEMI, while in the SYNTAX trial acute myocardial infarction was an exclusion criteria. Second, our mean follow-up was longer than in the SYNTAX trial (14.4 vs. 12 months). Finally, in our case series, the high rate of overall death was also caused by an increased number of non-cardiovascular deaths including neoplasms, infections or fatal traumas.

Our results are not in agreement with a recent review by Head et al. that found CABG has a mortality benefit over PCI, and this was associated with the anatomical SYNTAX score complexity (20). However, that review included studies in which PCI was also performed with bare metal stents (26.6\%) and first generation DES (39.2\%), and this might have impacted the outcome unfavourably; moreover, data from that review also demonstrated that 5-year all-cause mortality was similar after CABG or PCI, regardless of the degree of anatomical complexity, confirming the previous results of the EXCEL trial (21).

Our results also differ from those of Garg et al. showing that the SYNTAX score is able to stratify risk in a population of patients treated with PCI and second generation DES (22). However, the percentage of patients with multivessel disease, the SYNTAX score cutoff and the type of stent analyzed were different from those of our study population. A second interesting finding of our study is that we observed a low incidence of MACCE and other complications, such as CIN or major bleedings, at mid-term follow-up.

When we compared our results with those of multivessel patients enrolled in the SYNTAX study and treated with PCI, we observed that the incidence of TLR and MACCE were significantly lower in our study population: $2.7 \%$ versus $13.7 \%$ and $13.1 \%$ versus $17.8 \%$, respectively. Also comparing the subgroups of patients matched for SYNTAX score categories, the incidence of MACCE was significantly lower than that reported in the SYNTAX study: $13.6 \%, 16.7 \%$ and $23.4 \%$ in patients with low, intermediate and high scores in the SYNTAX trial, $8.3 \%, 14.3 \%$ and $16.7 \%$ in our population. Unlike the SYNTAX trial that reported a higher risk of cardiovascular events in patients with SYNTAX score $>22$, in our study population even patients with 
SYNTAX score $>22$ showed a very low incidence of adverse events, and the ROC curve analysis showed a higher cut-off of the score predicting cardiovascular events, equal to 29.75. These results suggest that the differences observed in patient outcome between our study and the SYNTAX trial are not exclusively ascribable to anatomical complexity.

There are several possible reasons for this: first of all, the relatively small sample size of our population could have favourably impacted the incidence of adverse events. Moreover, in our group of patients, the percentage of those with a SYNTAX score $>32$ was about $20 \%$ versus $33 \%$ in the SYNTAX study, and the mean value of the SYNTAX score was 24.5 versus 29, respectively. Another main difference was the kind of stent used in our patients: the Xience $\mathrm{V}$ stent instead of the now obsolete Taxus, a paclitaxel eluting stent (PES), which has not been used in daily practice since the availability of EES; the Xience V stent has a less inflammatory impact and, consequently, earlier coverage than the Taxus stent (23), and recent evidence suggests that EES is associated with a lower incidence of MACCE with respect to PES $(4-6,24,25)$. Moreover, in our population in a high percentage of patients $(86.5 \%)$ we achieved complete anatomical revascularization that is associated with a better outcome (26-28). Even if the concept of complete revascularization has mainly been emphasized as a point in favour of cardiac surgery, our results demonstrated, according to a recent study (29), that complete anatomical revascularization can be achieved in a high percentage of multivessel patients treated with PCI. The main reason for failure to achieve complete anatomic revascularization in our study population was represented by CTO not associated with regional ischemia (21 patients) or unsuccessful treatment with PCI (11 patients). Moreover, also the "complete revascularization" provided by CABG has limitations such as: 1) the proximal part of native coronary arteries bypassed frequently undergoes occlusion after the intervention; 2) when a stenosis is located before a bi- or trifurcation, only one branch is usually bypassed; 3 ) venous grafts have a short duration (30).
In addition, the radial artery as the first line approach in the majority of patients $(92.3 \%)$, with the consequent reduction in peripheral complications and bleedings, the choice of a tailored DAPT strategy, the systematic prevention of CIN with hyper-hydration, and the use of CRRT in patients with eGFR $<30 \mathrm{ml} / \mathrm{min}$, might have favourably impacted our patients' outcome, independently of the SYNTAX Class. With these considerations, we do not deny the importance of the anatomical complexity on the outcome of patients submitted to PCI, but we would like to underline that the results of PCI are due to a "sum of care", including not only the skills and the tools of interventional cardiologists, but also a holistic approach to the patients. Similarly, the patient's outcome is the result not only of anatomical complexity but also of other clinical potent factors that should be weighted in the choice of the revascularization strategy. In an attempt to consider these factors, after the conclusion of our study, a number of new predictive models, have been built with encouraging results (31). Among them, the SYNTAX score II combines the anatomical SYNTAX score with several clinical, demographic and functional variables $(8,9)$ and has superior results to the purely angiographic SYNTAX score in predicting 2 year and long-term mortality in patients with severe CAD, undergoing PCI or CABG $(10,11)$ also in diabetic patients (32-35). Moreover, SYNTAX II showed the ability to detect several clinical characteristics in favour of PCI or CABG (36-38). However, the search for more complete prognostic scores is continuing and more recently the SYNTAX score III has been introduced, which integrates comorbidities and anatomy with a functional assessment of stenotic lesions by means of fractional flow reserve $(39,40)$.

\section{Limitations of Study}

Our study retrospectively analyzed the data of multivessel patients who underwent PCI at our Institution in the course of one year. Our population was relatively small, unselected and heterogeneous regarding the clinical presentation of coronary dis- 
ease at hospital admission, including patients with stable angina, non-ST elevation ACS, and STEMI. However, by including patients with STEMI in our study population, we strengthened the importance of our results since MACCE, bleedings, access site complications and CIN are known to be usually higher in this group of patients than that we observed.

\section{Conclusions}

In our study of multivessel disease patients treated with PCI and Xience V stents, the SYNTAX score, that is an index of anatomic complexity, does not seem to be an independent predictor of MACCE or any other post-treatment outcome. Moreover, in our study population the incidence of MACCE is lower than that previously reported for multivessel disease patients treated with angioplasty and first generation DES. These results can be mainly ascribed to the technical characteristics of the new generation of stents implanted, as well as to the holistic approach carried out on our patients, which mainly consists of optimization of antiplatelet therapy, as well as procedural and periprocedural management. The continuous search for new predictive scores, considering not only anatomical complexity but also several clinical and functional factors to increase the accuracy of outcome, indirectly corroborate our results.

\section{What Is Already Known on this Topic:}

The SYNTAX trial demonstrated the superiority of coronary artery bypass graft $(C A B G)$ over percutaneous coronary intervention (PCI) in patients with multivessel and/or left main disease and a high SYNTAX score. However, in that trial, first generation drug eluting stents (DES) were used. The results of more recent studies exploring the use of second generation DES, with a better safety profile, have allowed interventional cardiologists to consider PCI even for more complex coronary disease patterns for which CABG should be recommended according to the SYNTAX trial.

\section{What this Study Adds:}

In patients with multivessel disease treated with PCI and second generation DES, the SYNTAX score is not an independent predictor of MACCE or any other post-treatment outcome. Moreover, in our study the incidence of MACCE was lower than that previously reported with first generation DES, with a higher percentage of complete revascularization. These results suggest that PCI with newer DES and optimized therapeutic and periprocedural management should also be considered in patients with a SYNTAX score higher than the cut-off suggested in the homonymous trial above which CABG would be recommended.

Authors' Contributions: Conception and design: CG, EC and NM; Acquisition, analysis and interpretation of data: MC and SMR; Drafting the article: $\mathrm{AM}, \mathrm{CZ}$ and $\mathrm{MB}$; Revising it critically for important intellectual content: CG, EC and NM; Approved final version of the manuscript: CG, EC and NM.

Conflict of Interest: The authors declare that they have no conflict of interest.

\section{References}

1. Serruys PW, Morice MC, Kappetein AP, Colombo A, Holmes DR, Mack MJ, et al. Percutaneous coronary intervention versus coronary-artery bypass grafting for severe coronary artery disease. N Engl J Med. 2009;360(10):96172. Erratum in: N Engl J Med. 2013;368(6):584.

2. Mohr FW, Morice MC, Kappetein AP, Feldman TE, Ståhle E, Colombo A, et al. Coronary artery bypass graft surgery versus percutaneous coronary intervention in patients with three-vessel disease and left main coronary disease: 5 -year follow-up of the randomised, clinical SYNTAX trial. Lancet. 2013;381(9867):629-38.

3. Head SJ, Davierwala PM, Serruys PW, Redwood SR, Colombo A, Mack MJ, et al. Coronary artery bypass grafting vs. percutaneous coronary intervention for patients with three-vessel disease: final five-year follow-up of the SYNTAX trial. Eur Heart J. 2014;35(40):2821-30.

4. Kereiakes DJ, Smits PC, Kedhi E, Parise H, Fahy M, Serruys $\mathrm{PW}$, et al. Predictors of death or myocardial infarction, ischaemic-driven revascularisation, and major adverse cardiovascular events following everolimus-eluting or paclitaxel-eluting stent deployment: pooled analysis from the SPIRIT II, III, IV and COMPARE trials. EuroIntervention. 2011;7(1):74-83.

5. Dangas GD, Serruys PW, Kereiakes DJ, Hermiller J, Rizvi A, Newman W, et al. Meta-analysis of everolimus-eluting versus paclitaxel-eluting stents in coronary artery disease: final 3-year results of the SPIRIT clinical trials program (Clinical Evaluation of the Xience V Everolimus Eluting Coronary Stent System in the Treatment of Patients With De Novo Native Coronary Artery Lesions). JACC Cardiovasc Interv. 2013;6(9):914-22.

6. Gada H, Kirtane AJ, Newman W, Sanz M, Hermiller JB, Mahaffey KW, et al. 5-year results of a randomized comparison of XIENCE V everolimus-eluting and TAXUS Paclitaxel-eluting stents: final results from the SPIRIT III trial (clinical evaluation of the XIENCE V everolimus eluting coronary stent system in the treatment of patients with de novo native coronary artery lesions). JACC Cardiovasc Interv. 2013;6(12):1263-6. 
7. Park SJ, Ahn JM, Kim YH, Park DW, Yun SC, Lee JY, et al. Trial of Everolimus-Eluting Stents or Bypass Surgery for Coronary Disease. N Engl J Med. 2015;372(13):1204-12.

8. Yadav M, Palmerini T, Caixeta A, Madhavan MV, Sanidas E, Kirtane AJ, et al. Prediction of coronary risk by SYNTAX and derived scores: synergy between percutaneous coronary intervention with taxus and cardiac surgery. J Am Coll Cardiol. 2013;62(14):1219-30.

9. Farooq V, Head SJ, Kappetein AP, Serruys PW. Widening clinical applications of the SYNTAX Score. Heart. 2014;100(4):276-87.

10. Song Y, Gao Z, Tang X, Ma Y, Jiang P, Xu J, et al. Usefulness of the SYNTAX score II to validate 2-year outcomes in patients with complex coronary artery disease undergoing percutaneous coronary intervention: A large singlecenter study. Catheter Cardiovasc Interv. 2018;92(1):40-7.

11. Xu B, Genereux P, Yang Y, Leon MB, Xu L, Qiao S, et al. Validation and comparison of the long-term prognostic capability of the SYNTAX score-II among 1,528 consecutive patients who underwent left main percutaneous coronary intervention. JACC Cardiovasc Interv. 2014;7(10):1128-37.

12. Roques F, Nashef SA, Michel P, Gauducheau E, de Vincentiis C, Baudet E, et al. Risk factors and outcome in European cardiac surgery: analysis of the EuroSCORE multinational database of 19030 patients. Eur J Cardiothorac Surg. 1999;15(6):816-22.

13. Task Force on Myocardial Revascularization of the European Society of Cardiology (ESC) and the European Association for Cardio-Thoracic Surgery (EACTS); European Association for Percutaneous Cardiovascular Interventions (EAPCI), Wijns W, Kolh P, Danchin N, Di Mario $\mathrm{C}$, et al. Guidelines on myocardial revascularization. Eur Heart J. 2010;31(20):2501-55.

14. Ong AT, Serruys PW. Complete revascularization: coronary artery bypass graft surgery versus percutaneous coronary intervention. Circulation. 2006;114(3):249-55.

15. Aradi D, Komócsi A, Price MJ, Cuisset T, Ari H, Hazarbasanov D, et al. Tailored Antiplatelet Treatment Study Collaboration. Efficacy and safety of intensified antiplatelet therapy on the basis of platelet reactivity testing in patients after percutaneous coronary intervention: systematic review and meta-analysis. Int J Cardiol. 2013;167(5):2140-8.

16. Cecchi E, Marcucci R, Chiostri M, Mecarocci V, Spini $\mathrm{V}$, Innocenti L, et al. Dual antiplatelet therapy tailored on platelet function test after coronary stent implantation: a real-world experience. Intern Emerg Med. 2015;10(7):805-14.

17. Thygesen K, Alpert JS, Jaffe AS, Simoons ML, Chaitman BR, White HD, et al. Joint ESC/ACCF/AHA/WHF Task Force for Universal Definition of Myocardial Infarction. Third universal definition of myocardial infarction. J Am Coll Cardiol. 2012;60(16):1581-98.

18. Stone GW, Ellis SG, Cox DA, Hermiller J, O’Shaughnessy C, Mann JT, et al. A polymer-based, paclitaxel-eluting stent in patients with coronary artery disease. $\mathrm{N}$ Engl J Med. 2004;350(3):221-31.

19. Mehran R, Rao SV, Bhatt DL, Gibson CM, Caixeta A, Eikelboom J, et al. Standardized bleeding definitions for cardiovascular clinical trials. A consensus report from the Bleeding Academic Research Consortium. Circulation. 2011;123(23):2736-47.

20. Head SJ, Milojevic M, Daemen J, Ahn JM, Boersma E, Christiansen EH, et al. Mortality after coronary artery bypass grafting versus percutaneous coronary intervention with stenting for coronary artery disease: a pooled analysis of individual patient data. Lancet. 2018; 10;391(10124):939-48.

21. Stone GW, Sabik JF, Serruys PW, Simonton CA, Généreux P, Puskas J, et al. Everolimus-eluting stents or bypass surgery for left main coronary artery disease. N Engl J Med. 2016;8;375(23):2223-35.

22. Garg S, Serruys PW, Silber S, Wykrzykowska J, van Geuns RJ, Richardt G, et al. The prognostic utility of the SYNTAX score on 1-year outcomes after revascularization with zotarolimus- and everolimus eluting stents: a substudy of the RESOLUTE All Comers Trial. JACC Cardiovasc Interv. 2011;4(4):432-41.

23. Otsuka F, Vorpahl M, Nakano M, Foerst J, Newell JB, Sakakura K, et al. Pathology of second-generation everolimus eluting stents versus first-generation sirolimusand paclitaxel-eluting stents in humans. Circulation. 2014;129(2):211-23.

24. Gada H, Kirtane AJ, Newman W, Sanz M, Hermiller JB, Mahaffey KW, et al. 5-Year results of a randomized comparison of XIENCE V everolimus-eluting and TAXUS paclitaxel-eluting stents: final results from the SPIRIT III trial (clinical evaluation of the XIENCE V everolimus eluting coronary stent system in the treatment of patients with de novo native coronary artery lesions). JACC Cardiovasc Interv. 2013;6(12):1263-6.

25. Onuma Y, Kukreja N, Piazza N, Eindhoven J, Girasis C, Schenkeveld L, et al. The everolimus-eluting stent in real-world patients: 6-month follow-up of the X-SEARCH (Xience V Stent Evaluated at Rotterdam Cardiac Hospital) registry. J Am Coll Cardiol. 2009;54(3):269-76.

26. Archbold RA, Robinson NM, Schilling RJ. Radial artery access for coronary angiography and percutaneous coronary intervention. BMJ. 2004;329(7463):443-6.

27. Hannan EL, Wu C, Walford G, Holmes DR, Jones RH, Sharma $S$, et al. Incomplete revascularization in the era of drug-eluting stents: impact on adverse outcomes. JACC Cardiovasc Interv. 2009;2(1):17-25.

28. Farooq V, Serruys PW, Garcia-Garcia HM, Zhang Y, Bourantas CV, Holmes DR, et al. The negative impact of incomplete angiographic revascularization on clinical outcomes and its association with total occlusions: the SYNTAX (Synergy Between Percutaneous Coronary Intervention with Taxus and Cardiac Surgery) trial. J Am Coll Cardiol. 2013;61(3):282-94. 
29. Xu B, Yang YJ, Han YL, Lu SZ, Li B, Liu Q, et al. Validation of residual SYNTAX score with second-generation drugeluting stents: one-year results from the prospective multicentre SEEDS study. EuroIntervention. 2014;10(1):6573.

30. Ahn JM, Park DW, Lee CW, Chang M, Cavalcante R, Sotomi Y, et al. Comparison of Stenting Versus Bypass Surgery According to the Completeness of Revascularization in Severe Coronary Artery Disease. JACC Cardiovasc Interv. 2017;10(14):1415-24.

31. Head SJ, Farooq V, Serruys PW, Kappetein AP. The SYNTAX score and its clinical implications. Heart. 2014;100(4):169-77.

32. Campos CM, van Klaveren D, Iqbal J, Onuma Y, Zhang YJ, Garcia-Garcia HM, et al. Predictive Performance of SYNTAX Score II in Patients With Left Main and Multivessel Coronary Artery Disease-analysis of CREDOKyoto registry. Circ J. 2014;78(8):1942-9.

33. Campos CM, Garcia-Garcia HM, van Klaveren D, Ishibashi Y, Cho YK, Valgimigli M, et al. Validity of SYNTAX score II for risk stratification of percutaneous coronary interventions: A patient-level pooled analysis of 5,433 patients enrolled in contemporary coronary stent trials. Int J Cardiol. 2015;187:111-5.

34. Stanetic BM, Ostojic M, Campos CM, Marinkovic J, Farooq V, Kovacevic-Preradovic T, et al. ApPropriateness of myocaRdial RevascularizatiOn assessed by the SYNTAX score II in a coUntry without cardiac Surgery faciliTies; PROUST study. Int J Cardiol. 2017;227:478-84.

35. Cavalcante R, Sotomi Y, Mancone M, Whan Lee C, Ahn JM, Onuma Y, et al. Impact of the SYNTAX scores I and II in patients with diabetes and multivessel coronary disease: a pooled analysis of patient level data from the SYNTAX, PRECOMBAT, and BEST trials. Eur Heart J. 2017;38(25):1969-77.

36. Campos CM, van Klaveren D, Farooq V, Simonton CA, Kappetein AP, Sabik JF 3rd, et al. Long-term forecasting and comparison of mortality in the Evaluation of the Xience Everolimus Eluting Stent vs. Coronary Artery Bypass Surgery for Effectiveness of Left Main Revascularization (EXCEL) trial: prospective validation of the SYNTAX Score II. Eur Heart J. 2015;36(20):1231-41.

37. Farooq V, van Klaveren D, Steyerberg EW, Meliga E, Vergouwe Y, Chieffo A, et al. Anatomical and clinical characteristics to guide decision making between coronary artery bypass surgery and percutaneous coronary intervention for individual patients: development and validation of SYNTAX score II. Lancet. 2013;381(9867):639-50.

38. Sotomi Y, Cavalcante R, van Klaveren D, Ahn JM, Lee CW, de Winter RJ, et al. Individual Long-Term Mortality Prediction Following Either Coronary Stenting or Bypass Surgery in Patients With Multivessel and/or Unprotected Left Main Disease: An External Validation of the SYNTAX Score II Model in the 1,480 Patients of the BEST and PRECOMBAT Randomized Controlled Trials. JACC Cardiovasc Interv. 2016;9(15):1564-72.

39. Serruys PW, Chichareon P, Modolo R, Leaman DM, Reiber JHC, Emanuelsson H, et al. The SYNTAX score on its way out or ... towards artificial intelligence: part I. EuroIntervention. 2020;16(1):44-59.

40. Collet C, Onuma Y, Andreini D, Sonck J, Pompilio G, Mushtaq S, et al. Coronary computed tomography angiography for heart team decision-making in multivessel coronary artery disease. Eur Heart J. 2018;39(41):3689-98. 